\title{
Gut microbiome in cirrhotic hepatitis C virus patients with and without hepatocellular carcinoma
}

\author{
Khaled Mohieldeen ${ }^{1}$, Soraya Abdel Fatah Hamoda', Shwikar Mahmoud Ahmed², Abdurrahman Najeeb ${ }^{1 *}$ (D) and \\ Walid Ismail Ellakany ${ }^{1}$
}

\begin{abstract}
Background: Chronic hepatitis $C$ is the most common cause of chronic liver disease and hepatocellular carcinoma in Egypt. A pathogenic link with gut microbial dysbiosis has been described in different diseases. The aim of the study is to elucidate changes in gut microbiome in cirrhotic HCV Egyptian patients with and without HCC.

Results: The study included 50 cirrhotic HCV patients; 25 with and 25 without HCC and 25 healthy controls with matched age and sex. Stool specimens were taken from all participants. Quantitative SYBR Green real-time PCR technique targeting 165 rRNA was done for the identification and quantitation of selected bacterial phylum, genera, and/or species. Both HCC and cirrhosis groups showed decrease in Firmicutes, F/B ratio, A. mucinophilia, and F. prausnitzii compared to the control group. However, the HCC group only showed statistically significant increase in Bacteroides and Lactobacilli, and decrease of Prevotella relative abundance and P/B ratio compared to both cirrhosis and control groups. As regard the relation between the gut microbiome and stages of HCC, BCLC stage D showed significantly the lowest relative abundance of Ruminococcus.
\end{abstract}

Conclusion: Patients with HCV-related cirrhosis and HCC exhibit microbial dysbiosis; altered microbial relative abundance and diversity with HCC patients showing higher proinflammatory bacteria compared to cirrhotics.

Keywords: Cirrhosis, Hepatitis C virus, Hepatocellular carcinoma, Gut dysbiosis

\section{Background}

Hepatitis $\mathrm{C}$ virus (HCV) prevalence is estimated to be 71 million cases globally [1]. Infection is often asymptomatic, but chronic infection can lead to cirrhosis, liver failure, and hepatocellular carcinoma ( $\mathrm{HCC})$ and the need for liver transplantation.

Egypt has high prevalence of HCV genotype 4 [2]. However, after the state-wide test-and-treat program, the prevalence was found to be lower than previously thought [3]. HCV treatment with the new direct-acting antivirals (DAAs) offered high SVR

\footnotetext{
* Correspondence: a_najeeb13@alexmed.edu.eg

${ }^{1}$ Tropical Medicine Department, Faculty of Medicine, Alexandria University, Alexandria, Egypt

Full list of author information is available at the end of the article
}

rates (> 95\%) and short treatment course with minimal side effects.

The past few years witnessed an increased interest in the gut microbiota, its composition and its role in health and diseases [4]. Gut dysbiosis was associated with local and distal carcinogenesis either directly or indirectly [5-8]. Microbiota carcinogenic and toxic metabolites potentiate inflammation or immunosuppression $[9,10]$. They also enhance our anti-tumor immunity against various cancers [11-13].

The gut microbiota comprises mainly the phylotypes, Bacteroidetes, and Firmicutes. Actinobacteria (like Bifidobacterium spp.), Proteobacteria (like Escherichia coli), and Verrucomicrobia (like Akkermansia muciniphila) are less abundant but are associated with some diseases. The microbiota synthesize vitamins, help digestion, and

\section{Springer Open}

(๑) The Author(s). 2021 Open Access This article is licensed under a Creative Commons Attribution 4.0 International License, which permits use, sharing, adaptation, distribution and reproduction in any medium or format, as long as you give appropriate credit to the original author(s) and the source, provide a link to the Creative Commons licence, and indicate if changes were made. The images or other third party material in this article are included in the article's Creative Commons licence, unless indicated otherwise in a credit line to the material. If material is not included in the article's Creative Commons licence and your intended use is not permitted by statutory regulation or exceeds the permitted use, you will need to obtain permission directly from the copyright holder. To view a copy of this licence, visit http://creativecommons.org/licenses/by/4.0/. 
boost immunity [14, 15]. They strengthen gut barrier epithelial integrity [16], harvest energy [17], and protect against external pathogens [18].

Association of the gut microbiota with development of hepatic diseases has drawn interest [19]. Most gastrointestinal tract drains into portal vein that enters the liver carrying about two thirds of its blood supply. Besides absorbed nutrients, it can contain gut microbial metabolites, lipopolysaccharides, bacterial endotoxins, or other substances, especially when the intestinal barrier is deranged by dysbiosis. Translocation of products can lead to hepatic inflammation, with release of key inflammatory mediators such as NF-kB and TLR4. This chronic inflammation can foster the initiation and progression of malignancies [20-23].

\section{Aim of the work}

The aim of this study was to elucidate changes in gut microbiome in cirrhotic HCV Egyptian patients. This may help in the development of new approaches for treatment and prevention of $\mathrm{HCC}$ by modulating the gut microbiome.

\section{Subjects}

The study was carried out in Alexandria Main University Hospital. The study included 50 cirrhotic HCV Egyptian patients; 25 with and 25 without HCC who were recruited from the Tropical Medicine Department at Alexandria Main University Hospital and 25 Egyptian healthy subjects with matched age and sex as control group.

\section{Exclusion criteria}

Malignancy other than HCC, HBV, and other hepatic diseases; recent surgical intervention of the intestines either small or large within the last 6 months; infectious diarrhea including bacterial, viral, and parasitic diarrhea; history of prolonged use of antibiotics, rifaximin, nonsteroidal anti-inflammatory drugs abuse, corticosteroids for the last 3 months; other autoimmune diseases, pregnancy, chronic renal diseases, diabetes mellitus, alcohol or substance addiction; patients unable to give consent as mentally challenged.

\section{Methods}

\section{Clinical data and investigations}

Detailed history was taken from patients and controls with special emphasis on dietary and drug history. All patients and controls were subjected to full clinical examination. Body weight and height were measured, and body mass index was calculated. Cirrhotics were classified by Child-Pugh class (CPC) [24] into class A, B, and $C$ and the updated Barcelona Clinic Liver Cancer (BCLC) classification [25] was used to stratify HCC patients (Table 1). Laboratory investigations including
Table 1 Demographic, clinical, and laboratory characteristics of participants

\begin{tabular}{llll}
\hline & HCC $(\boldsymbol{n}=\mathbf{2 5})$ & Cirrhosis $(\boldsymbol{n}=\mathbf{2 5})$ & Controls $(\boldsymbol{n}=\mathbf{2 5})$ \\
\hline Age & $57.20 \pm 6.26$ & $61.80 \pm 9.34$ & $61.0 \pm 7.07$ \\
Males & $15(60 \%)$ & $19(76 \%)$ & $11(44 \%)$ \\
BMI & $26.68 \pm 3.44$ & $28.04 \pm 2.68$ & $28.28 \pm 4.26$ \\
Child-Pugh & & & \\
\multicolumn{1}{c}{ A } & $3(12 \%)$ & $6(24 \%)$ & \\
B & $12(48 \%)$ & $13(52 \%)$ & \\
C & $10(40 \%)$ & $6(24 \%)$ & \\
BCLC & & & \\
\multicolumn{1}{c}{ A } & $2(8 \%)$ & & \\
B & $10(40 \%)$ & \\
C & $8(32 \%)$ & & \\
D & $5(20 \%)$ & & \\
Hb & $12.82 \pm 14.02$ & $10.38 \pm 2.24$ & \\
Platelets & $79.0(55.0-101.0)$ & $104.0(62.0-136.0)$ & \\
WBC & $4.56(2.83-5.20)$ & $5.70(3.51-8.43)$ & \\
AST & $75.0(42.0-91.0)$ & $44.0(30.0-59.0)$ & \\
Albumin & $2.50 \pm 0.89$ & $2.51 \pm 0.52$ & \\
Bilirubin & $2.40(1.30-4.30)$ & $1.70(1.0-3.10)$ & \\
INR & $1.46 \pm 0.44$ & $1.41 \pm 0.22$ & \\
ALT & $37.0(33.0-42.0)$ & $26.0(19.0-42.0)$ & \\
AFP & $777.5 \pm 451.1$ & & \\
\hline Mean \pm SD is expressed as $n \pm n$ while median (IOR) is expressed as $n(n-n)$
\end{tabular}

serum Albumin, ALT, AST, bilirubin, AFP, INR, and $\mathrm{CBC}$ was obtained. Ultrasound was done for all patients. HCC cases were defined by AFP and triphasic CT.

\section{Gut microbiome analysis}

Specimen collection, preservation, and transport

Stool samples collected from cases and controls were delivered immediately to Alexandria University Main Microbiology Laboratory and stored at $-80{ }^{\circ} \mathrm{C}$ for further processing. Whenever a delay in transfer is anticipated, the subject was asked to keep it in the freezer at $-18{ }^{\circ} \mathrm{C}$ to be delivered frozen within the same day to the laboratory.

\section{DNA extraction}

DNA was extracted from 180-220 mg stool sample using QIAamp ${ }^{\circ}$ Fast DNA Stool Mini Kit (Qiagen, Germany) according to the manufacturers' instructions. DNA extracts were stored at $-80{ }^{\circ} \mathrm{C}$ until PCR testing.

\section{SYBR Green real-time PCR}

Specific oligonucleotide primers were used to target the 16S rRNA gene (rDNA) sequences of selected phyla, genera, or species constituting the gut microbiota $(A$. 
mucinophilia, Bacteroides, Prevotella, Ruminococcus, Bacteroidetes, Firmicutes, F. prausnitzii, Bifidobacterium, and Lactobacillus). In addition to a broad-range primer targeting conserved 16S rRNA sequence of total bacteria, the amplification of which served as the denominator against which the amplification of other bacteria was estimated. All of the primer sequences used are listed in Suppl. Table 1 [26-30]. Primers were commercially obtained (Invitrogen, USA).

Amplification was performed in a light cycler (Rotor Gene Q, Qiagen, Germany) using a SensiFAST ${ }^{\mathrm{TM}}$ SYBR No-ROX PCR kit (Bioline Co., UK). In short, forward and reverse primers ( $4 \mathrm{pmol}$ each) were used in $20 \mu \mathrm{l} \mathrm{re-}$ actions containing $2 \mu \mathrm{l}$ of the DNA extract.

PCR amplification was performed with initial denaturation at $95{ }^{\circ} \mathrm{C}$ for $10 \mathrm{~min}$, followed by 40 cycles of denaturation at $95{ }^{\circ} \mathrm{C}$ for $30 \mathrm{~s}$, annealing at $60{ }^{\circ} \mathrm{C}$ for $30 \mathrm{~s}$, and extension at $72{ }^{\circ} \mathrm{C}$ for $30 \mathrm{~s}$. Melting curve analysis was performed from 40 to $95{ }^{\circ} \mathrm{C}$ with a plate-reading step after every $1{ }^{\circ} \mathrm{C}$ and held at a temperature for $10 \mathrm{~s}$ to check the specificity of the product formed. Quantitation of specific bacterial DNA was expressed as relative quantitation (the cycle threshold $\left(C_{t}\right)$ at which DNA for a specific target was detected relative to the cycle threshold $\left(C_{t}\right)$ at which universal bacterial DNA was detected). This relative quantification is calculated automatically by the Rotor Gene software and expressed as relative fold difference [31].

The enterotype of all participants was determined according to the dominant type present of the three bacteria: Bacteroides (Enterotype 1), Prevotella (Enterotype 2), or Ruminococcus (Enterotype 3).

\section{Statistical analysis of the data}

Data entry and analysis were carried out using the Statistical Package for Social Sciences version 20 (SPPS PASW Statistics, Chicago). Quantitative variables were presented in the form of range, mean, median, and standard deviation. On the other hand, studied qualitative variables were presented as frequency and percentage from total. Comparisons between the different study groups were carried out using Chi-square, Fisher's exact, and Monte Carlo tests for qualitative variable and MannWhitney, Kruskal-Wallis tests for quantitative ones. For assessing correlations between different quantitative variables, Spearman correlation coefficient was calculated. All results were interpreted at $5 \%$ level of significance where the difference between the study groups is considered significant if $P$ is $\leq 0.05$. To evaluate the degree of variation of the microbial community structure within a sample, we measured the alpha diversity by employing the Shannon diversity index [32], and to evaluate the degree of similarity between patients and control group, we employed the Bray-Curtis similarity index [33].

\section{Results}

Characteristics of the participants

Out of the $25 \mathrm{HCC}$ patients, 15 (60\%) were males and 10 (40\%) were females, with male to female ratio of 1.5 : 1. Their mean age \pm SD was $57.20 \pm 6.26$ years, and their age ranged from 40-65 years. The BMI ranged between $20.0-32.0 \mathrm{~kg} / \mathrm{m}^{2}$ with mean $26.68 \pm 3.44 \mathrm{SD}$. Out of the 25 cirrhotic patients, 19 (76\%) were males and 6 (24\%) females, with male to female ratio of 3.1:1. Their mean age \pm SD was $61.80 \pm 9.34$ years, and their age ranged from 33-77 years. The BMI ranged between 22 and 32 $\mathrm{kg} / \mathrm{m}^{2}$ with mean $\pm \mathrm{SD}$ of $28.04 \pm 2.68$. Out of the 25 control subjects, 11 (44\%) were males and 14 (56\%) were females, with male to female ratio of $1: 1.2$. The mean age \pm SD of the cases was $61.0 \pm 7.07$, and their age ranged from 49-80 years. The BMI ranged between 19.28 and $37.11 \mathrm{~kg} / \mathrm{m}^{2}$ with mean \pm SD of $28.28 \pm 4.26$. There was no statistically significant difference between the 3 groups. In HCC, 3 (12\%) were CPS A, 12 (48\%) were CPS B, and 10 (40\%) were CPS C. In cirrhosis group, 6 (24\%) were CPS A, 13 (52\%) were CPS B, and 6 (24\%) were CPS C. There was no statistically significant difference between the 3 groups regarding these clinical parameters (Table 1). For BCLC staging of HCC, 2 (8\%) were in stage A, $10(40 \%)$ were in stage B, 8 (32\%) were in stage C, and $5(20 \%)$ were in stage D. Serum level of alanine aspartate aminotransferase (AST) was significantly higher in HCC cases compared to cirrhosis group $(p=0.035)$. Although the serum levels of alanine aminotransferase (ALT) and bilirubin were higher in HCC cases, the difference was not statistically significant $(p>$ 0.05). Also, the albumin and platelets levels were lower in HCC cases and the difference was not statistically significant (Table 1).

\section{Gut microbiome analysis}

Quantitation of specific bacteria DNA was not expressed as an absolute number but was expressed relative to the total bacteria DNA present in the stool sample. The relative abundance values of the various bacteria were shown in the following manner $\left(4.75 \times 10^{-5}\right.$ was shown as $4.75 \mathrm{E}-05)$.

\section{Phylum level analysis}

Bacterial phylum analysis showed that both patients with HCC and cirrhosis showed a statistically significant decrease in Firmicutes $(p<0.001)$, and although the Bacteroidetes was increased, the difference was not statistically significant in comparison to the control group. As regard the Firmicutes to Bacteroidetes ratio (F/B ratio), it was significantly lower in HCC (0.465) and cirrhosis patients $(0.260)$ versus 1.310 in the control subjects (Table 2, Fig. 1). 
Table 2 Comparison between the three studied groups according to Firmicutes to Bacteroidetes (F/B) ratio, Prevotella to Bacteroides $(\mathrm{P} / \mathrm{B})$ ratio, diversity index, and dissimilarity index (\%)

\begin{tabular}{|c|c|c|c|c|c|}
\hline & $\mathrm{HCC}(n=25)$ & Cirrhosis $(n=25)$ & Control $(n=25)$ & Test & $p$ \\
\hline \multicolumn{6}{|l|}{ F/B ratio } \\
\hline Min.-max. & $0.018-3.715$ & $0.020-10.550$ & $0.350-2.470$ & $H=15.699^{*}$ & $<0.001^{*}$ \\
\hline Mean \pm SD & $0.799 \pm 0.970$ & $1.229 \pm 2.562$ & $1.312 \pm 0.669$ & & \\
\hline Median (IQR) & $0.465(0.207-0.769)$ & $0.260(0.100-0.600)$ & $1.310(0.710-1.870)$ & & \\
\hline Significance between groups & \multicolumn{5}{|c|}{$p_{1}=0.337, p_{2}=0.004^{*}, p_{3}<0.001^{*}$} \\
\hline \multicolumn{6}{|l|}{$\mathrm{P} / \mathrm{B}$ ratio } \\
\hline Min.-max. & $0.000-2.205$ & $0.000-8.300$ & $0.010-4.490$ & $H=14.111^{*}$ & $0.001^{*}$ \\
\hline Mean \pm SD & $0.303 \pm 0.643$ & $1.519 \pm 2.270$ & $0.992 \pm 1.236$ & & \\
\hline Median (IQR) & $0.012(0.001-0.195)$ & $0.710(0.090-1.590)$ & $0.510(0.170-1.400)$ & & \\
\hline Significance between. groups & \multicolumn{5}{|c|}{$p_{1}=0.001^{*}, p_{2}=0.001^{*}, p_{3}=0.953$} \\
\hline \multicolumn{6}{|l|}{ Diversity index } \\
\hline Min.-max. & $0.75-1.68$ & $0.22-1.70$ & $1.14-1.70$ & $F=12.789^{*}$ & $<0.001^{*}$ \\
\hline Mean \pm SD & $1.25 \pm 0.27$ & $1.18 \pm 0.33$ & $1.53 \pm 0.12$ & & \\
\hline Median (IQR) & $1.31(1.06-1.45)$ & $1.23(0.98-1.36)$ & $1.56(1.48-1.60)$ & & \\
\hline Significance between. groups & \multicolumn{5}{|c|}{$p_{1}=0.611, p_{2}=0.001^{*}, p_{3}<0.001^{*}$} \\
\hline \multicolumn{6}{|l|}{ Dissimilarity index (\%) } \\
\hline Min.-max. & $24.0-85.0$ & 17.0-93.0 & $0.0-0.0$ & $F=101.434^{*}$ & $<0.001^{*}$ \\
\hline Mean \pm SD & $41.44 \pm 13.37$ & $43.64 \pm 16.38$ & $0.0 \pm 0.0$ & & \\
\hline Median (IQR) & $39.0(32.0-47.0)$ & $40.0(35.0-48.0)$ & $0.0(-)$ & & \\
\hline Significance between groups & \multicolumn{5}{|c|}{$p_{1}=0.800, p_{2}<0.001^{*}, p_{3}<0.001^{*}$} \\
\hline
\end{tabular}

$I Q R$, inter quartile range; $S D$, standard deviation; $H, \mathrm{H}$ for Kruskal-Wallis test, pairwise comparison between each 2 groups was done using post hoc test (Dunn's for multiple comparisons test); $F$, F for ANOVA test, pairwise comparison bet. each 2 groups was done using post hoc test (Tukey); $p, p$ value for comparing between the studied groups; $p_{1}, p$ value for comparing between $\mathrm{HCC}$ and cirrhosis; $p_{2}, p$ value for comparing between $\mathrm{HCC}$ and control; $p_{3}, p$ value for comparing between cirrhosis and control

*Statistically significant at $p \leq 0.05$

On the other hand, there was no statistically significant difference between HCC and cirrhosis group as regard Firmicutes, Bacteroidetes, and F/B ratio (Table 2, Fig. 1).

\section{Genus level analysis}

There was a statistically significant increase in Bacteroides and decrease of Prevotella relative abundance in HCC group compared to both cirrhosis and control groups. However, both cirrhosis and HCC groups showed a statistically significant decrease in Ruminococcus, in comparison to the control group. Also, there was no statistically significant difference between cirrhosis and control groups as regard $\mathrm{Bac}$ teroides and Prevotella, and between HCC and cirrhosis groups as regard Ruminococcus (Table 2, Fig. 1).

For the Prevotella-to-Bacteroides $(\mathrm{P} / \mathrm{B})$ ratio, there was no statistically significant difference between cirrhosis and the control groups. However, it was significantly lower in HCC (0.012) versus cirrhosis patients (0.71) and control subjects (0.51) (Table 2).

\section{Species level analysis}

As regard the beneficial bacteria, there was a statistically significant decrease in A. mucinophilia and F. prausnitzii in HCC and cirrhosis groups compared to the control group. Meanwhile, there was no statistical difference between HCC, cirrhosis, and control groups as regard Bifidobacteria. Also, there was no statistical difference between cirrhosis and control groups as regard Lactobacilli. On the other hand, there was a statistically significant increase in Lactobacilli relative abundance in HCC group compared to both the cirrhosis and control groups (Fig. 1).

\section{Alpha diversity}

Shannon diversity index, that considers both species richness and evenness, demonstrated a statistically significant low microbial diversity in both the HCC (1.25) and cirrhosis (1.18) groups compared to the control group (1.53). However, there was no statistically significant difference between the diversity index of $\mathrm{HCC}$ and cirrhosis patients (Table 2). 


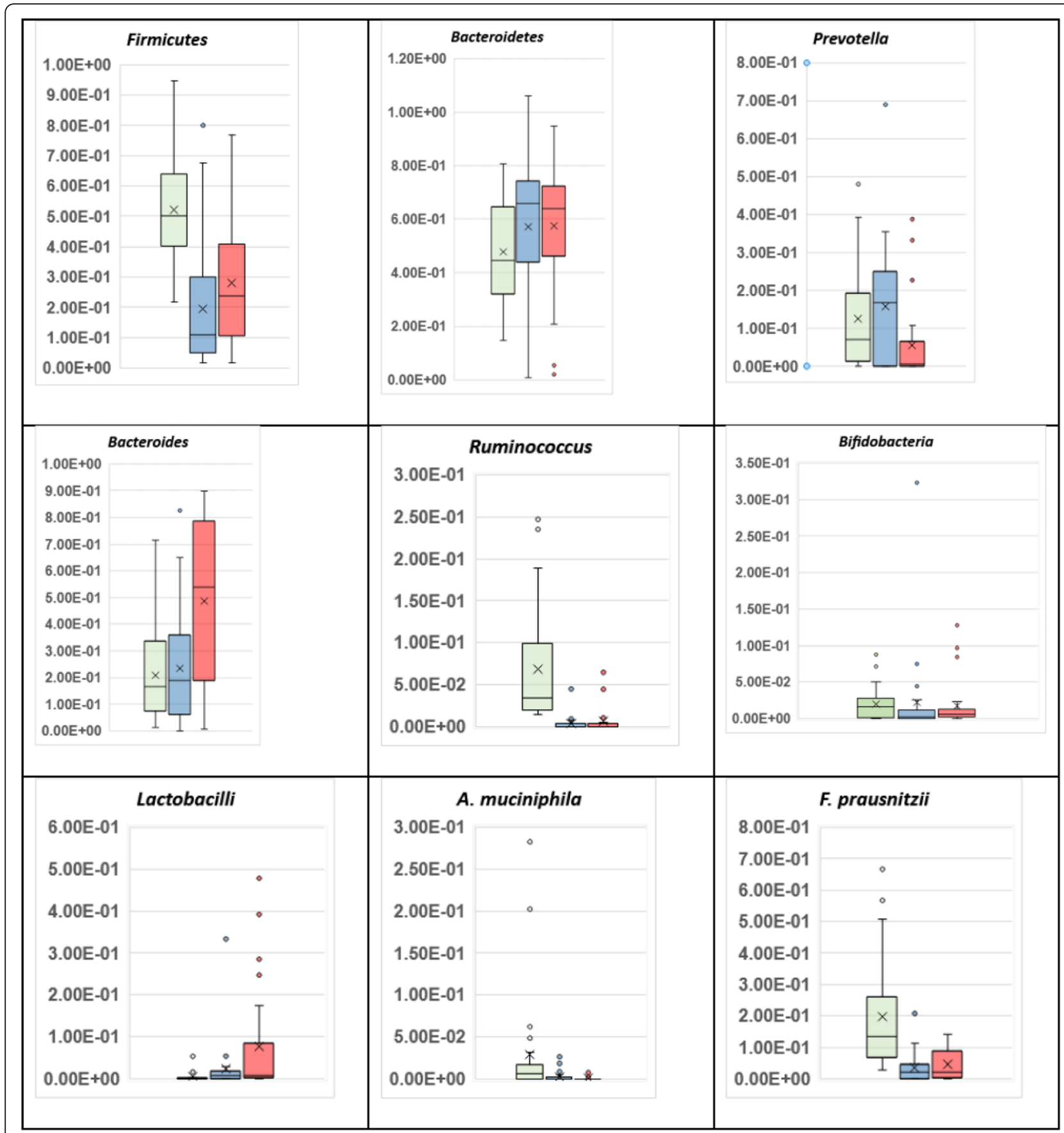

Fig. 1 Box and whisker graph of gut microbiome in the studied groups. The thick line in the middle of the box represents the median, the box represents the inter-quartile range (from 25th to 75th percentiles) and the whiskers represent the minimum and maximum. Control $\square$ Cirrhosis HCC $\square$

\section{Bray-Curtis dissimilarity index}

Bray-Curtis dissimilarity index was performed to study the degree of dissimilarity between microbiota in the HCC and cirrhosis groups compared to the control group. The dissimilarity index between HCC cases and healthy controls was $41.44 \%$. The dissimilarity index between cirrhosis group and healthy controls was $43.64 \%$. Comparing dissimilarity index between HCC and cirrhosis groups demonstrated no statistically significant difference ( $p=$ 0.8 ). On the other hand, the dissimilarity index between HCC and cirrhosis groups was only $26 \%$. This means that they are $74 \%$ like each other (Table 2). 


\section{Gut microbiome and the clinical stage}

In HCC group, there was no statistically significant difference between Child-Pugh class and the relative abundance of the studied microbiota, F/B ratio, $\mathrm{P} / \mathrm{B}$ ratio, diversity index, or dissimilarity index (Suppl. Table 2).

There was statistically significant difference between the BCLC stages of HCC and Ruminococcus relative abundance $(p=0.023)$. There was no statically significant difference between the BCLC stage of HCC and other bacteria, $\mathrm{F} / \mathrm{B}$ ratio, $\mathrm{P} / \mathrm{B}$ ratio, diversity index, and dissimilarity index (\%) (Suppl. Table 3).

In cirrhosis group, there was no statistically significant correlation between the Child-Pugh class and the relative abundance of each of the studied microbiota. Also, there was no statistically significant correlation between the Child-Pugh class and F/B ratio, $\mathrm{P} / \mathrm{B}$ ratio, diversity index, and dissimilarity index (\%) (Suppl. Table 4).

\section{The enterotypes of the study participants}

Enterotype 1 was the most common enterotype detected in all study participants. Twenty-two (88\%) of the 25 HCC patients were assigned to Enterotype 1, 3 (12\%) were assigned to Enterotype 2, and none to Enterotype 3 . For the 25 cirrhosis group cases, $15(60 \%)$ were assigned to Enterotype 1, 8 (32\%) were assigned to Enterotype 2, and 2 (8\%) were Enterotype 3. On the other hand, $13(52 \%)$ of the 25 control subjects were assigned to Enterotype 1, 9 (36\%) were assigned to Enterotype 2, and 3 (12\%) were Enterotype 3. There was no statistically significant difference between the 3 groups regarding the enterotype distribution. $(P$ value $=$ 0.053). However, Enterotype 1 was higher in HCC group than the control group $\left(P\right.$ value $\left.=0.016^{\prime \prime}\right)$. Also, Enterotype 1 is the predominant enterotype in HCC group $(P$ value $\left.=0.022^{\prime \prime}\right)$, while the control group showed insignificant higher Enterotype 1 followed Enterotype 2 ( $P$ value $<0.05$ ).

\section{Discussion}

Hepatocellular carcinoma (HCC) is the second leading cause of cancer-related mortality worldwide. Cirrhosis is the most important risk factor for HCC. However, the exact factors that impact cirrhosis progression to HCC need to be determined [34].

Recent studies have noticed that Hepatitis $\mathrm{C}$ virus (HCV) infection and the progression of hepatic cirrhosis are associated with gut dysbiosis. Progressive changes in the gut microbiome have been observed accompanying the progression of liver disease $[35,36]$.

The present study agrees with the previous studies as regard decreased diversity and gut dysbiosis [35, 37, 38]. All HCV infected cases whether cirrhotic or with HCC showed gut dysbiosis and decreased diversity compared to healthy controls. The pattern of dysbiosis in both HCC and cirrhosis groups showed a significantly lower relative abundance of butyrate-producing bacteria Firmicutes, F/B ratio, and the bacteria maintaining the gut barrier function by enhancing mucus production, $A$. mucinophilia and $F$. prausnitzii, compared to the control group. However, the HCC group differed from the cirrhotic in that they showed statistically significant more increase in the proinflammatory genus Bacteroides and Lactobacilli and marked decrease of butyrate producer and anti-inflammatory genus Prevotella relative abundance and $\mathrm{P} / \mathrm{B}$ ratio compared to both cirrhosis and control groups. The decrease of Prevotella and $\mathrm{P} / \mathrm{B}$ ratio is a potential biomarker for liver disease progression. Bacteroides and Lactobacilli were associated with deconjugating bile acids by their bile salt hydrolase enzyme and causing liver damage [39].

Other studies showed a similar pattern of dysbiosis that is linked to inflammation. Pinero et al. (2019) in their study of 25 cirrhotic and 25 HCC cases noticed decreased Prevotella and $\mathrm{P} / \mathrm{B}$ ratio in HCC compared to cirrhotic. However, in their study, there was no significant change in Bacteroides which may be due to different dietary pattern of their population [40].

Ponziani et al. (2019) found that NAFLD-related HCC patients had increased inflammatory cytokines related with a higher abundance of Bacteroides and Ruminococcaceae and a fall in beneficial bacteria such as Akkermansia. They also noticed decrease in the $\mathrm{P} / \mathrm{B}$ ratio in these HCC patients compared to liver cirrhosis and healthy subjects [41]. Also, Chen et al. (2011), in their study of 36 cirrhotic and 24 controls, also noticed decreased F. prausnitzii in cirrhotic but no decreased Firmicutes [35].

In an Egyptian study (2016) on six HCV patients and eight healthy individuals, Aly et al. found that $\mathrm{HCV}$ patients showed a significantly lower relative abundance of Firmicutes. However, in contrast to our study, Prevotella, Faecalibacterium, and Bacteroidetes were more abundant in $\mathrm{HCV}$ patients compared to healthy individuals which may be related to the sample size [42].

As regard Lactobacilli, our results coincide with that of Inoue et al. (2018) who found that chronic hepatitis C patients had an increase in Lactobacillus [22]. Also, Sydor S et al. (2020) found that Lactobacilli was more abundant in NASH-related HCC than in cirrhotics [43].

As regard the relation between the gut microbiome and stages of HCC, BCLC stage D showed significantly the lowest relative abundance of Ruminococcus. This supports the suggestion that the progression of disease is associated with the decrease of anti-inflammatory butyrate producing bacteria and increase of proinflammatory bacteria. 
Understanding the composition of gut microbiota in $\mathrm{HCV}$ patients may help in the development of new approaches for treatment and prevention of HCC by modulating the gut microbiome. GM-CSF can protect against $\mathrm{HCC}$ by its effect on immunity and microbiota composition and metabolism as demonstrated in mice [44].

Our diet influence the enterotype in our gut; high-fat and protein diet enhances the growth of Enterotypes 1, while a diet rich in carbohydrates supports the raise of Enterotype 2 and high fiber diet vegetables with Enterotype 3 [45]. Many studies showed the abundance of Enterotype 1 in countries depending on the Western diet which is associated with increased inflammation and increased gut inflammatory cells [46].

In the present study, Enterotype 1 is the dominant in all our study groups and significantly higher in HCC cases than control group ( $88 \%$ versus 52\%). On the other hand, Enterotype 2 was the least enterotype encountered in HCC group; only 3 cases are Enterotype 2.

The gut microbiota may reduce cancer progression by regulating the ICD (immunogenic cell death) pathway, and increase the anticancer effects of drugs. Strategies making use of the gut microbiota such as probiotics and fecal microbiota transplantation (FMT) may act as potential adjuvants for tumor immunotherapy [47]. Yamamoto et al. found that gut microbiota in HCC patients before sorafenib may aid to prevent or delay its side effects [48].

Our results contribute to the knowledge of the possible association between the gut microbiota and the progression of hepatic diseases. Understanding the composition of gut microbiota in HCV patients may help in the development of new approaches for treatment and prevention of HCC by modulating the gut microbiome.

Our study is a single-center study and was performed on 75 subjects. Multi-center studies on heterogeneous larger population can be done in the future.

\section{Conclusions}

The overall results of the present study confirmed that patients with HCV-related cirrhosis and HCC exhibit microbial dysbiosis. Altered microbial relative abundance and diversity was noted vs controls. At the genus level, the HCC patients showed higher proinflammatory bacteria pattern compared to cirrhotic patients. These data imply that the changed gut microbiota may represent a potential target to monitor and prevent HCC development by the gut-microbiota-liver axis. The decrease of Prevotella and P/B ratio could be used as potential biomarker for liver disease progression.

\section{Abbreviations}

HCC: Hepatocellular carcinoma; HCV: Hepatitis C virus; DAAs: Direct-acting antivirals; SVR: Sustained virological response; CPC: Child-Pugh class;
BCLC: Barcelona Clinic Liver Cancer; F/B ratio: Firmicutes to Bacteroidetes ratio; $\mathrm{P} / \mathrm{B}$ ratio: Prevotella to Bacteroides ratio

\section{Supplementary Information}

The online version contains supplementary material available at https://doi. org/10.1186/s43066-021-00147-y.

Additional file 1: Supplementary Table (1). Primers used in the present study. Supplementary Table (2). Relation between Child score and gut microbiome in HCC group. Supplementary Table (3). Relation between HCC-BCLC stage and gut microbiome. Supplementary Table (4). Relation between Child-Pugh Score and gut microbiome in cirrhosis group

\section{Acknowledgements}

The authors would like to thank all patients for their participation in this research.

Authors' contributions

KM: Research design, draft writing, data analysis, and critically reviewed the manuscript. SH: Research design, draft writing, and critically reviewed the manuscript. AN: Research design, recruitment of patients, data collection, and draft writing. SA: Research design, performed the lab work, analysis and interpretation of the gut microbiome PCR results, participated in draft writing, and critically reviewed the manuscript. WE: Concept, draft writing, data analysis, and critically reviewed the manuscript. All authors have read and approved the manuscript.

Funding

The authors declare no funds, grants, or other support was received.

Availability of data and materials

Data used to support the findings of this study are included within the article and supplementary data.

\section{Declarations}

Ethics approval and consent to participate

The study follows the principles of the Declaration of Helsinki (6th revision, 2008). After approval of the Ethical Committee, Faculty of Medicine, Alexandria University (serial no. 0201306), informed consents were obtained from all patients expressing their acceptance to participate in the study and have the results published.

Consent for publication

Written informed consents were obtained from both patients and control. Patient involved in this study agree for publication of data.

\section{Competing interests}

The authors declare that they have no competing interests.

\section{Author details}

${ }^{1}$ Tropical Medicine Department, Faculty of Medicine, Alexandria University, Alexandria, Egypt. ${ }^{2}$ Medical Microbiology and Immunology Department, Faculty of Medicine, Alexandria University, Alexandria, Egypt.

Received: 30 July 2021 Accepted: 13 September 2021

Published online: 28 September 2021

\section{References}

1. Organization WH (2017) Global hepatitis report 2017. Geneva: World Health Organization

2. Centers for Disease Control and Prevention (CDC) (2012) Progress toward prevention and control of hepatitis C virus infection--Egypt, 2001-2012. MMWR Morb Mortal Wkly Rep 61(29):545-9.

3. Waked I, Esmat G, Elsharkawy A, El-Serafy M, Abdel-Razek W, Ghalab R et al (2020) Screening and treatment program to eliminate hepatitis $C$ in Egypt. N Engl J Med 382(12):1166-1174. https://doi.org/10.1056/NEJMsr1912628 
4. Cresci GA, Bawden E (2015) Gut microbiome: what we do and don't know Nutr Clin Pract 30(6):734-746. https://doi.org/10.1177/0884533615609899

5. Dzutsev A, Badger JH, Perez-Chanona E, Roy S, Salcedo R, Smith CK, Trinchieri G (2017) Microbes and cancer. Annu Rev Immunol 35(1):199-228. https://doi.org/10.1146/annurev-immunol-051116-052133

6. Shahanavaj K, Gil-Bazo I, Castiglia M, Bronte G, Passiglia F, Carreca AP, del Pozo JL, Russo A, Peeters M, Rolfo C (2015) Cancer and the microbiome: potential applications as new tumor biomarker. Expert Rev Anticancer Ther 15(3):317-330. https://doi.org/10.1586/14737140.2015.992785

7. Arthur JC, Perez-Chanona E, Mühlbauer M, Tomkovich S, Uronis JM, Fan T-J, Campbell BJ, Abujamel T, Dogan B, Rogers AB, Rhodes JM, Stintzi A, Simpson KW, Hansen JJ, Keku TO, Fodor AA, Jobin C (2012) Intestinal inflammation targets cancer-inducing activity of the microbiota. Science 338(6103):120-123. https://doi.org/10.1126/science.1224820

8. Zitvogel L, Galluzzi L, Viaud S, Vétizou M, Daillère R, Merad M et al (2015) Cancer and the gut microbiota: an unexpected link. Sci Transl Med 7(271): 271ps1-ps1

9. Yu L-X, Schwabe RF (2017) The gut microbiome and liver cancer: mechanisms and clinical translation. Nat Rev Gastroenterol Hepatol 14(9): 527-539. https://doi.org/10.1038/nrgastro.2017.72

10. Helmink BA, Khan MAW, Hermann A, Gopalakrishnan V, Wargo JA (2019) The microbiome, cancer, and cancer therapy. Nat Med 25(3):377-388. https://doi.org/10.1038/s41591-019-0377-7

11. Morkūnas E, Skiecevičienè J, Kupčinskas J (2020) The impact of modulating the gastrointestinal microbiota in cancer patients. Best Pract Res Clin Gastroenterol 101700:101700. https://doi.org/10.1016/j.bpg.2020.101700

12. Zitvogel L, Daillère R, Roberti MP, Routy B, Kroemer G (2017) Anticancer effects of the microbiome and its products. Nat Rev Microbiol 15(8):465478. https://doi.org/10.1038/nrmicro.2017.44

13. Daillère $R$, Vétizou $M$, Waldschmitt $N$, Yamazaki $T$, Isnard $C$, Poirier-Colame $V$, Duong CPM, Flament C, Lepage P, Roberti MP, Routy B, Jacquelot N, Apetoh L, Becharef S, Rusakiewicz S, Langella P, Sokol H, Kroemer G, Enot D, Roux A, Eggermont A, Tartour E, Johannes L, Woerther PL, Chachaty E, Soria JC, Golden E, Formenti S, Plebanski M, Madondo M, Rosenstiel P, Raoult D, Cattoir V, Boneca IG, Chamaillard M, Zitvogel L (2016) Enterococcus hirae and Barnesiella intestinihominis facilitate cyclophosphamide-induced therapeutic immunomodulatory effects. Immunity. 45(4):931-943. https:// doi.org/10.1016/j.immuni.2016.09.009

14. Gensollen T, lyer SS, Kasper DL, Blumberg RS (2016) How colonization by microbiota in early life shapes the immune system. Science. 352(6285):539544. https://doi.org/10.1126/science.aad9378

15. Guarner F, Malagelada J-R (2003) Gut flora in health and disease. Lancet 361(9356):512-519. https://doi.org/10.1016/S0140-6736(03)12489-0

16. Natividad JMM, Verdu EF (2013) Modulation of intestinal barrier by intestinal microbiota: pathological and therapeutic implications. Pharmacol Res 69(1): 42-51. https://doi.org/10.1016/j.phrs.2012.10.007

17. den Besten G, van Eunen K, Groen AK, Venema K, Reijngoud D-J, Bakker BM (2013) The role of short-chain fatty acids in the interplay between diet, gut microbiota, and host energy metabolism. J Lipid Res 54(9):2325-2340. https://doi.org/10.1194/jlr.R036012

18. Bäumler AJ, Sperandio V (2016) Interactions between the microbiota and pathogenic bacteria in the gut. Nature. 535(7610):85-93. https://doi.org/10.1 038/nature18849

19. Acharya C, Sahingur SE, Bajaj JS (2017) Microbiota, cirrhosis, and the emerging oral-gut-liver axis. JCl Insight 2(19):e94416. https://doi.org/10.11 72/jci.insight.94416

20. Bhat M, Arendt BM, Bhat V, Renner EL, Humar A, Allard JP (2016) Implication of the intestinal microbiome in complications of cirrhosis. World J Hepatol 8(27):1128-1136. https://doi.org/10.4254/wjh.v8.i27.1128

21. Tsochatzis EA, Bosch J, Burroughs AK (2014) Liver cirrhosis. Lancet 383(9930): 1749-1761

22. Inoue T, Nakayama J, Moriya K, Kawaratani H, Momoda R, Ito K, lio E, Nojiri S, Fujiwara K, Yoneda M, Yoshiji H, Tanaka Y (2018) Gut dysbiosis associated with hepatitis C virus infection. Clin Infect Dis 67(6):869-877. https://doi. org/10.1093/cid/ciy205

23. Darnaud M, Faivre J, Moniaux N (2013) Targeting gut flora to prevent progression of hepatocellular carcinoma. J Hepatol 58(2):385-387. https:// doi.org/10.1016/j.jhep.2012.08.019

24. Pugh RN, Murray-Lyon IM, Dawson JL, Pietroni MC, Williams R (1973) Transection of the oesophagus for bleeding oesophageal varices. Br J Surg 60(8):646-649. https://doi.org/10.1002/bjs.1800600817
25. Forner A, Reig M, Bruix J (2018) Hepatocellular carcinoma. Lancet 391(10127):1301-1314. https://doi.org/10.1016/S0140-6736(18)3001 $0-2$

26. Nadkarni MA, Martin FE, Jacques NA, Hunter N (2002) Determination of bacterial load by real-time PCR using a broad-range (universal) probe and primers set. Microbiology 148(Pt 1):257-266

27. Collado MC, Derrien M, Isolauri E, de Vos WM, Salminen S (2007) Intestinal integrity and Akkermansia muciniphila, a mucin-degrading member of the intestinal microbiota present in infants, adults, and the elderly. Appl Environ Microbiol 73(23):7767-7770. https://doi.org/10.1128/AEM.01477-07

28. Bergström A, Licht TR, Wilcks A, Andersen JB, Schmidt LR, Grønlund HA, Vigsnaes LK, Michaelsen KF, Bahl MI (2012) Introducing GUt low-density array (GULDA): a validated approach for qPCR-based intestinal microbial community analysis. FEMS Microbiol Lett 337(1):38-47. https://doi.org/1 $0.1111 / 1574-6968.12004$

29. Rinttilä T, Kassinen A, Malinen E, Krogius L, Palva A (2004) Development of an extensive set of $16 \mathrm{~S}$ rDNA-targeted primers for quantification of pathogenic and indigenous bacteria in faecal samples by real-time PCR. J Appl Microbiol 97(6):1166-1177. https://doi.org/10.1111/j.1365-2672.2004. 02409.x

30. Ramirez-Farias C, Slezak K, Fuller Z, Duncan A, Holtrop G, Louis P (2009) Effect of inulin on the human gut microbiota: stimulation of Bifidobacterium adolescentis and Faecalibacterium prausnitzii. Br J Nutr 101(4):541-550. https://doi.org/10.1017/S0007114508019880

31. Tomova A, Husarova V, Lakatosova S, Bakos J, Vlkova B, Babinska K, Ostatnikova D (2015) Gastrointestinal microbiota in children with autism in Slovakia. Physiol Behav 138:179-187. https://doi.org/10.1016/j.physbeh.2 014.10 .033

32. Shannon CE (1948) A mathematical theory of communication. Bell Sys Techn J 27(3):379-423. https://doi.org/10.1002/j.1538-7305.1948.tb01338.x

33. Bray JR, Curtis JT (1957) An ordination of the upland forest communities of Southern Wisconsin. Ecol Monogr 27(4):325-349. https://doi.org/10.2307/1 942268

34. Balogh J, Victor D 3rd, Asham EH, Burroughs SG, Boktour M, Saharia A et al (2016) Hepatocellular carcinoma: a review. J Hepatocellular Carcinoma 3:4153. https://doi.org/10.2147/JHC.S61146

35. Chen Y, Yang F, Lu H, Wang B, Chen Y, Lei D et al (2011) Characterization of fecal microbial communities in patients with liver cirrhosis. Hepatology 54(2):562-572

36. Bajaj JS, Heuman DM, Hylemon PB, Sanyal AJ, White MB, Monteith P, Noble NA, Unser AB, Daita K, Fisher AR, Sikaroodi M, Gillevet PM (2014) Altered profile of human gut microbiome is associated with cirrhosis and its complications. J Hepatol 60(5):940-947. https://doi.org/10.1016/j.jhep.2 013.12 .019

37. Ren Z, Li A, Jiang J, Zhou L, Yu Z, Lu H, Xie H, Chen X, Shao L, Zhang R, Xu S, Zhang H, Cui G, Chen X, Sun R, Wen H, Lerut JP, Kan Q, Li L, Zheng S (2019) Gut microbiome analysis as a tool towards targeted non-invasive biomarkers for early hepatocellular carcinoma. Gut. 68(6):1014-1023. https:// doi.org/10.1136/gutjnl-2017-315084

38. Zheng R, Wang G, Pang Z, Ran N, Gu Y, Guan X, Yuan Y, Zuo X, Pan H, Zheng J, Wang F (2020) Liver cirrhosis contributes to the disorder of gut microbiota in patients with hepatocellular carcinoma. Cancer Med 9(12): 4232-4250. https://doi.org/10.1002/cam4.3045

39. Gérard $P$ (2013) Metabolism of cholesterol and bile acids by the gut microbiota. Pathogens. 3(1):14-24. https://doi.org/10.3390/pathogens301 0014

40. Piñero F, Vazquez M, Baré P, Rohr C, Mendizabal M, Sciara M, Alonso C, Fay F, Silva M (2019) A different gut microbiome linked to inflammation found in cirrhotic patients with and without hepatocellular carcinoma. Ann Hepatol 18(3):480-487. https://doi.org/10.1016/j.aohep.2018.10.003

41. Ponziani FR, Bhoori S, Castelli C, Putignani L, Rivoltini L, Del Chierico F et al (2019) Hepatocellular carcinoma is associated with gut microbiota profile and inflammation in nonalcoholic fatty liver disease. Hepatology 69(1):107120

42. Aly AM, Adel A, El-Gendy AO, Essam TM, Aziz RK (2016) Gut microbiome alterations in patients with stage 4 hepatitis C. Gut Pathog 8(1):42. https:// doi.org/10.1186/s13099-016-0124-2

43. Sydor S, Best J, Messerschmidt I, Manka P, Vilchez-Vargas R, Brodesser S et al (2020) Altered microbiota diversity and bile acid signaling in cirrhotic and noncirrhotic NASH-HCC. Clin Transl Gastroenterol 11(3):e00131-e 
44. Wu Y-N, Zhang L, Chen T, Li X, He L-H, Liu G-X (2020) Granulocytemacrophage colony-stimulating factor protects mice against hepatocellular carcinoma by ameliorating intestinal dysbiosis and attenuating inflammation. World J Gastroenterol 26(36):5420-5436. https://doi.org/10.3 748/wjg.v26.i36.5420

45. Arumugam M, Raes J, Pelletier E, Le Paslier D, Yamada T, Mende DR et al (2011) Enterotypes of the human gut microbiome. Nature. 473(7346):174180. https://doi.org/10.1038/nature09944

46. Thorburn Alison N, Macia L, Mackay CR (2014) Diet, metabolites, and "Western-Lifestyle" inflammatory diseases. Immunity. 40(6):833-842. https:// doi.org/10.1016/j.immuni.2014.05.014

47. Chen W, Wang S, Wu Y, Shen X, Guo Z, Li Q, Xing D (2020) Immunogenic cell death: a link between gut microbiota and anticancer effects. Microb Pathog 141:103983. https://doi.org/10.1016/j.micpath.2020.103983

48. Yamamoto K, Kuzuya T, Honda T, Ito T, Ishizu Y, Nakamura M et al (2020) Relationship between adverse events and microbiomes in advanced hepatocellular carcinoma patients treated with sorafenib. Anticancer Res 40(2):665-676. https://doi.org/10.21873/anticanres.13996

\section{Publisher's Note}

Springer Nature remains neutral with regard to jurisdictional claims in published maps and institutional affiliations.

\section{Submit your manuscript to a SpringerOpen ${ }^{\circ}$ journal and benefit from:}

- Convenient online submission

- Rigorous peer review

- Open access: articles freely available online

- High visibility within the field

Retaining the copyright to your article

Submit your next manuscript at $\boldsymbol{\nabla}$ springeropen.com 